\title{
Accessible Websites for Everyone - A Case of UAE Universities Websites
}

\author{
Liaqat Ali
}

\begin{abstract}
Web Accessibility means that websites, tools, and all technologies are designed in an accessible way for all people regardless of any disability and other physical limitations. The number of disabled people is far greater than anyone could estimate. The importance of online education cannot be ignored as it can provide access to a range of educational material available over the internet. There is now much discussion about the issue of E-accessibility when it comes the to the design and development of the website and it is becoming a legal requirement for governmental and public websites to conform with the standards defined by the world wide web consortium (W3C), an organization which provides guidelines to maintain World Wide Web and its standards. Research proved that there is very little importance given to the issue of E-accessibility for people with special needs. The aim of this research is therefore to measure the accessibility level of the educational websites in the UAE against the standard defined by W3C and to form recommendations on how to improve and achieve the highest level of e-accessibility for students with special needs learners as it provides them easy access to a wider range of educational material. Enabling a website to meet the needs and requirements of special students is a concern for all educational institutions.
\end{abstract}

Index Terms-E-accessibility, WCAG, W3C, websites, education, universities, e-learning.

\section{INTRODUCTION}

The power of the Web is in its universality. Access by everyone regardless of disability is an essential aspect [1]. Education must enable each and every person access and the ability to acquire knowledge, which is useful to themselves [2]. The World Wide Web Consortium (W3C), Web Accessibility Initiative (WAI) provides guidelines for web standards and plays a critical role in achieving the highest level of E-accessibility for people with disabilities. To make sure that everyone can access information over the internet, the World Wide Web Consortium has developed a series of guidelines to maintain the accessibility level and to overcome the barriers of E-accessibility. Usability is critical for a website as it keeps the users comfortable when using or browsing the website [3].

The first series of these guidelines, Web Content Accessibility Guidelines 1.0, were developed in the form of recommendations on 5th May 1999 [4]. Initially, these guidelines were divided into 65 checkpoints with three different priority levels, extracted from [4]. These priority

Manuscript received May 8, 2020; revised December 26, 2020.

Liaqat Ali is with the Department of Information Technology, College of Engineering and Information Technology, University of Science and Technology of Fujairah, P.O. Box: 2202, Fujairah, United Arab Emirates (e-mail: 1.ali@ustf.ac.ae). levels are;

Priority 1 - A Web content developer must satisfy this checkpoint. Otherwise, one or more groups will find it impossible to access information in the document. Satisfying this checkpoint is a basic requirement for some groups to be able to use Web documents.

Priority 2 - Web content developer should satisfy this checkpoint. Otherwise, one or more groups will find it difficult to access information in the document. Satisfying this checkpoint will remove significant barriers to accessing Web documents.

Priority 3- A Web content developer may address this checkpoint. Otherwise, one or more groups will find it somewhat difficult to access information in the document. Satisfying this checkpoint will improve access to Web documents.

The second version of WCAG 2.0 was published in the form of recommendations on 11th December 2008 by W3C [5]. These guidelines were divided into four different categories for the above mentioned three priority levels, perceivable, operable, understandable, and robust. The third version of the guideline WCAGE 2.1 which is an extension to WCAG 2.0 guidelines was introduced recently on 5th June 2018 [6]. 'The publication of WCAG 2.1 does not deprecate or supersede WCAG 2.0. While WCAG 2.0 remains a W3C Recommendation, the W3C advises the use of WCAG 2.1 to maximize future applicability of accessibility efforts' [6].

\section{E-ACCESSIBILITY BARRIERS}

Disabled people encounter many restrictions during their attempt to access online services [7]. Different disabilities are considered to be the barriers in E-accessibility when it comes to the development of websites. Statistics also show that normal people use websites or online services three times more than those suffering from disabilities [8]. An important issue to understand is that all disabilities do not affect the way of e-accessibility. However, there is still a necessity to develop further research for those with cognitive impairments and disabilities due to the increasing popularity of e-learning [9]. For example, a person paralyzed with legs still can access the web over the internet and it will not be considered as an accessibility barrier. However, other disabilities can affect the way of e-accessibility. These are divided into four different types. These are;

1) Visual disabilities

2) Hearing disabilities

3) Learning disabilities

4) Limited physical control

It is important to consider that the number of disabled 
people is far greater than one can envisage. According to the World Health Organization (WHO) the global data on visual impairments [10], the estimated number of people visually impaired in the world is 285 million, 39 million blind and 246 million having low vision. This is reflected in Fig. 1 below, extracted from [10]. Further studies proved that there are an estimated 466 million people around the world with hearing disabilities [11]. Also, in 2017-18, the number of students ages 3-21 who received special education services under the Individuals with Disabilities Education Act (IDEA) was 7.0 million, or 14 percent of all public school students. Among students receiving special education services, 34 percent had specific learning disabilities [12].

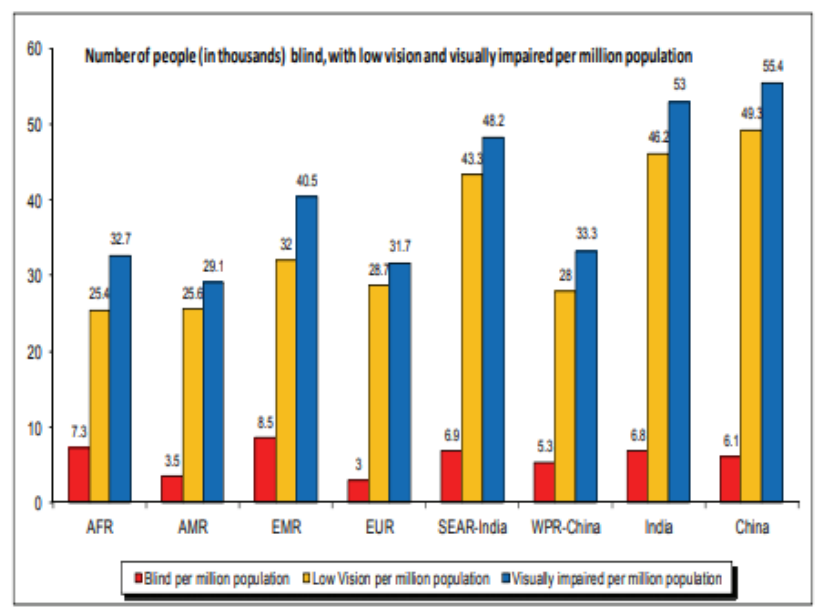

Fig. 1. Number of Visually Disabled People around the world. Source: [10]

\section{E-ACCESSIBILITY TOOLS}

E-Accessibility tools play an important role in achieving the highest level of E-accessibility during the development and designing of websites. These tools help web developers and designers for the assessment and validations of websites and to ensure that accessibility standards and guidelines standardized by $\mathrm{W} 3 \mathrm{C}$ are implemented appropriately and to further make sure that the information on these websites is accessible to a large number of people regardless of any disability and physical limitations. One of the most important aspects that must be considered when utilizing these tools that E-accessibility tools do not provide a complete result about the accessibility of a tested and validated website. A manual test of accessibility standard is therefore important when measuring the level of e-accessibility of any website and its contents. A plethora of E-accessibility tools is there where every tool provides the result of accessibility standards as per their interpretations. There are 136 E-accessibility tools listed on the website of W3C [13]. However, the standardization of these accessibility tools is another issue to be considered here as sometimes tools generate completely different results from one another. Therefore, the importance of the manual testing process cannot be ignored. Accessibility Testing Tools are categorized as:

- Screen Reader Software: Read out the contents on the screen

- Speech Recognition Software: Converts the spoken words into text
- Special Keyboard: Ease of typing using this keyboard especially people with motor impairments

- Screen Magnification Software: Dedicated to vision-impaired users thus it is used to enlarge the display such that the reading will be easier.

Some of the important E-accessibility tools includes PACT, A-Checker, Cynthia Says, UCD-manager, Total Validator, Test-Page, Site-improve Intelligence Platform, TAW, uTester, WAVE, The A11Y Compliance Platform, Web AccChecker, DYNO Mapper, Automated Accessibility Testing Tool, SortSite, OWA, Mobile Web Accessibility Checker, Tenon, Vamolà, Accessibility Checklist, MAUVE, Access Analytics, Access Alchemy, Accessibility Developer Tools, Accessibility Insights for Web, Accessibility Viewer, Opquast desktop, Accessible Brand Colors 2.1, AccessIn, Domain Accessibility Audit, DubBot, HTML_CodeSniffer, Free Web Accessibility Check, HeadingsMap, EqualWeb and many more.

\section{Assistive TeChNOLOGIES}

Assistive technology is a generic term that describes tools used by people with disabilities to accomplish tasks. They provide enhancements and changed methods of interacting with technology, which is needed to support those suffering from disabilities [14]. Assistive technology is a set of devices intended to help people who have disabilities. Many assistive devices are built using artificial intelligence (AI) technologies, including real-time text-to-speech transcription and visual recognition tools.

Table I below provides a summary of assistive devices that helps to overcome the accessibility barriers as per their types.

TABLE I: TYPES OF DISABILITY AND ASSISTIVE TECHNOLOGY

\begin{tabular}{|l|l|}
\hline $\begin{array}{l}\text { Type of } \\
\text { Disability }\end{array}$ & Assistive Technology \\
\hline $\begin{array}{l}\text { Visual } \\
\text { Disability }\end{array}$ & $\begin{array}{l}\text { Screen readers, Voice browser, Videos, PDFs, } \\
\text { Desktop video magnifiers, Large print keyboard, } \\
\text { Wearable technology, Themes }\end{array}$ \\
\hline $\begin{array}{l}\text { Physical } \\
\text { Disability }\end{array}$ & $\begin{array}{l}\text { Web Application, Eye Tracking, Head pointers, } \\
\text { Scanning software }\end{array}$ \\
\hline Hearing & $\begin{array}{l}\text { Sound notification, Captions and Subtitles for Video, } \\
\text { visual signals, sound AMPR App }\end{array}$ \\
\hline Learning & $\begin{array}{l}\text { Text readers, Writing and reading assistant, Speech } \\
\text { Disability }\end{array}$ \\
\hline
\end{tabular}

\section{A CASE of United ARAB EMIRATES (UAE)}

The UAE Federal Government Web Guidelines are intended to improve the quality, consistency, and reach of the internal and external online communications carried out by the UAE Federal Government and all its Entities. These guidelines are meant to help bring coherence to UAE Federal Government messaging on the internet and to ensure that all websites and associated web channels are in line with international standards, making them easy to access, use and understand [15]. The guidelines were developed by combining the vast online experience and expertise already within the UAE Federal Government with World Wide Web Consortium (W3C) and ISO standards. These Web Guidelines are primarily for web design, information services, and marketing and communications of websites, not for 
technical aspects and transactional services of websites.

UAE is now becoming the hub of the financial world and much of the information is available electronically. The awareness among government and public sector websites about the issues of e-accessibility is now growing. In UAE only, according to the World Health Organization, 11 percent of the population has some sort of disability [16].

Fig. 2, below reflects the number of registered disable students in the universities of UAE from the year 2013 to 2017. However, the actual number of disabled people could be far larger than this.

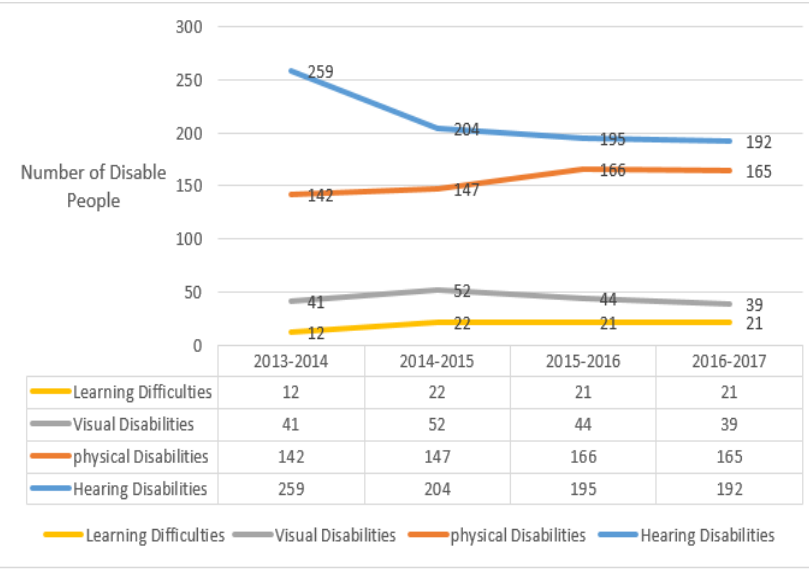

Fig. 2. Estimated registered disabled students in UAE from 2013-2017 Source: [17].

\section{Research Methodology}

The research of this paper considered the home pages of the university websites in the UAE. The researcher conducted the e-accessibility level test against WCAG 2.0. As discussed in the above sections, E-accessibility evaluation tools are available which can measure the level of the website's accessibility. However, a manual check is still required before drawing any conclusion for this research.

On the other hand, the selection of the right e-accessibility tool is a challenge because of the plethora of design. There are many tools available where some are commercial and others are open source. The research in this paper didn't rely on the result of one tool and therefore used three different tools to measure the e-accessibility level of the websites. After conducting the test by these three tools their results are accumulated and manual checks have been formed to measure the level of e-accessibility of the selected universities websites of the UAE. The tools used are;

A-Checker: Accessibility Checker was developed in 2009 by the University of Toronto where the accessibility of the web pages could be evaluated against the HTML Validator, BITV, Section 508, Stanca Act, WCAG 1.0 and WCAG 2.0. The tool could be found on the link https://achecker.ca/checker/index.php

Cynthia Says: The Compliance Sheriff Cynthia Say Portal is a joint education and outreach project of Compliance Sheriff, ICDRI, and the Internet Society Disability and Special Needs Chapter. Cynthia Says educates you on the concepts behind website accessibility. It is meant for personal, non-commercial use to inform the community on what constitutes accessible web design and accessible content. It identifies errors in Web content related to Section 508 standards and/or the WCAG guidelines for Web accessibility. Cynthia Says allows you to test individual pages on websites and provides feedback in a reporting format that is clear and easy to understand. Using this free service will expose you to the underlying technology and benefits of using Compliance Sheriff's full-featured solutions for automated monitoring and testing against Web accessibility and other Web governance standards. The tool could be found at http://www.cynthiasays.com/

TAW: TAW references WCAG 1.0, 2.0, and its own set of own heuristics for mobile accessibility. Developed by the CTIC Centro Tecnólogico, TAW clearly marks the accessibility violations that it discovers by providing an annotated version of the website as well as recommendations on how to resolve them. It is available online and as a desktop application as well as a Firefox add-on. The tool could be found

at http://www.webdevstuff.com/103/taw-web-accessibility-test .html.

The below Table II provides a short comparison of the tools used for this research.

TABLE II: TOOLS COMPARISON OF A-CHECKER, CYNTHIA SAYS, AND TAW

\begin{tabular}{|c|c|c|c|c|c|c|c|c|c|c|c|c|c|}
\hline Tool & URL & File & Paste & WCAG1.0 & WCAG2.0 & Sec 508 & Format & Language & License & $\begin{array}{l}\text { Online } \\
\text { Service }\end{array}$ & $\begin{array}{l}\text { Information } \\
\text { updated }\end{array}$ & $\begin{array}{l}\text { Browser } \\
\text { plugins }\end{array}$ & $\begin{array}{l}\text { WCAG } \\
2.1\end{array}$ \\
\hline A-Checker & $\sqrt{ }$ & $\sqrt{ }$ & $\sqrt{ }$ & $\sqrt{ }$ & $\sqrt{ }$ & $\sqrt{ }$ & $\begin{array}{l}\text { CSS, } \\
\text { HTML, } \\
\text { XHTML }\end{array}$ & $\begin{array}{l}\text { English, } \\
\text { German } \\
\text { (Deutsch), } \\
\text { Italian } \\
\text { (Italiano) }\end{array}$ & $\begin{array}{l}\text { Free } \\
\text { Software, } \\
\text { Open Source }\end{array}$ & $\begin{array}{l}\text { Online } \\
\text { checker, } \\
\text { Hosted } \\
\text { service }\end{array}$ & 2018-Sep-19 & & \\
\hline $\begin{array}{l}\text { Cynthia } \\
\text { Says }\end{array}$ & $\sqrt{ }$ & & & $\sqrt{ }$ & $\sqrt{ }$ & $\sqrt{ }$ & $\begin{array}{l}\text { CSS, } \\
\text { HTML, } \\
\text { Images }\end{array}$ & English & $\begin{array}{l}\text { Free } \\
\text { Software }\end{array}$ & $\begin{array}{l}\text { Online } \\
\text { checker }\end{array}$ & 2017-Feb-25 & & \\
\hline TAW & $\sqrt{ }$ & & $\sqrt{ }$ & $\sqrt{ }$ & $\sqrt{ }$ & & $\begin{array}{l}\text { WAI-ARIA, } \\
\text { CSS, } \\
\text { HTML, } \\
\text { XHTML, } \\
\text { Images }\end{array}$ & $\begin{array}{l}\text { English, } \\
\text { Portuguese } \\
\text { (Português), } \\
\text { Spanish } \\
\text { (Castellano) }\end{array}$ & $\begin{array}{l}\text { Free } \\
\text { Software, } \\
\text { Commercial, } \\
\text { Enterprise }\end{array}$ & $\begin{array}{l}\text { Online } \\
\text { checker }\end{array}$ & 2019-Sep-26 & & $\sqrt{ }$ \\
\hline
\end{tabular}

As discussed, a manual check of these websites been formed by the researcher to make sure that the result is more authentic and accurate.
Then the data from semi-structured interviews are used to draw the organizational approach to improve the e-accessibility level of the university website. For the 
collection of data, the researcher travelled to many UAE universities and semi-structured interviews were conducted with the IT departments to understand the policies and efforts made by the universities for students with special needs. The following were the questions asked during the process of interviews:

1) Do you think e-accessibility is an important part of website design and development?

2) How far do you consider E-accessibility and its guidelines when designing or developing a website for the university?

3) Do you have any policy developed about the e-accessibility of websites in your university?

4) Do you conduct any e-accessibility awareness and training programs at your University?

5) What efforts are made by your university to improve the awareness and consideration of E-accessibility required by students with special needs?

6) Have you seen any process in the university that could help improve the e-accessibility level of your website and other educational content?

7) Are you aware of any circumstances or challenges that special needs students faced when collecting online information through your website or any other educational material provided by the university in an online environment?

8) According to your experience, what resources and tools are the most effective to improve the level of e-Accessibility?

9) In your opinion, how the content of the website of your university could be made more accessible to students with special needs.

10) What best practices do you recommend to improve the e-accessibility level of the websites of the university?

\section{FINDINGS AND DATA ANALYSIS}

As discussed above, this research tested and validated university websites in UAE to measure the accessibility level of the web pages for students with disabilities.

In total, 103 University URL's were collected. However, due to some technical problems, the tools used in this research didn't show any result for the 16 university websites. The author, therefore, removed these from the manual check as well. The data of these universities are kept confidential for the purpose of further research.

For other 87 University websites, the accessibility tests were conducted according to the standard of the Web Content Accessibility Guidelines (WCAG 2.0) Principles 1, 2, 3, and 4. The tested websites of the UAE universities contain main E-leaning home pages. The homepages of the university websites were validated and tested with the help of e-accessibility tools, A-Checker, Cynthia Says, and TAW.

The findings of this research as per Fig. 3 below show that only $6 \%$ of university websites completely conform with the Level A, AA, and AAA conformance of WCAG 2.0 while 94\% failed to achieve any standard of conformance.

Further analysis as per Fig. 4 below shows that:

Known Problems
- $10 \%$ of websites conform to the standard of Level A of WCAG 2.0 and $90 \%$ of websites didn't achieve the level which is the minimum standard.

E-Accessibility Result Of Universities Websites in UAE

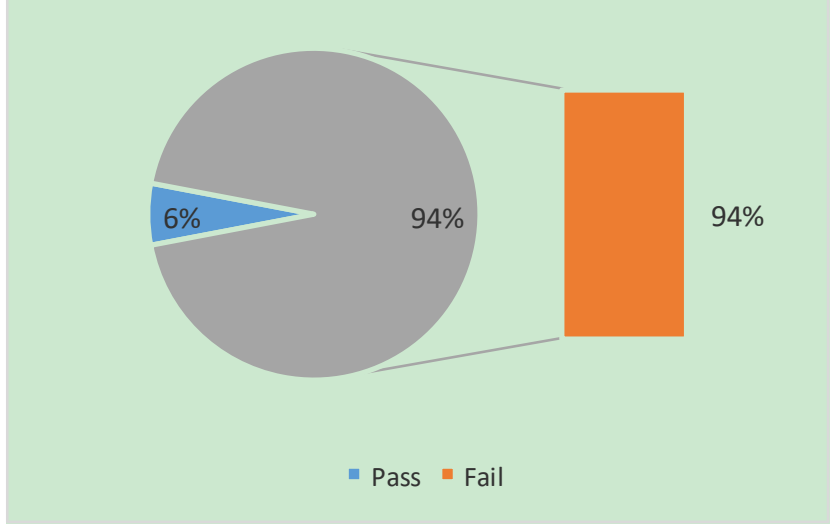

Fig. 3. E-accessibility Results of Universities Websites in UAE Source: The author of this research.

- 7\% of websites conform to the standard of Level AA of WCAG 2.0 and $93 \%$ of websites didn't achieve the standard

- $7 \%$ of websites conform to the standard of Level AAA of WCAG 2.0 and 93\% didn't achieve the standard.

\section{Likely Problems}

- $67 \%$ of websites conform to the standard of Level A of WCAG 2.0 and $33 \%$ of websites didn't achieve the level.

- $63 \%$ of websites conform to the standard of Level AA of WCAG 2.0 and $37 \%$ of websites didn't achieve the level.

- $66 \%$ of websites conform to the standard of Level AAA of WCAG 2.0 and 34\% didn't achieve the level.

\section{Potential Problems}

- $6 \%$ of websites conform to the standard of Level A of WCAG 2.0 and $94 \%$ of websites didn't achieve the level.

- $6 \%$ of websites conform to the standard of Level AA of WCAG 2.0 and $94 \%$ of websites didn't achieve the level.

- $6 \%$ of websites conform to the standard of Level AAA of WCAG 2.0 and 94\% didn't achieve the level.

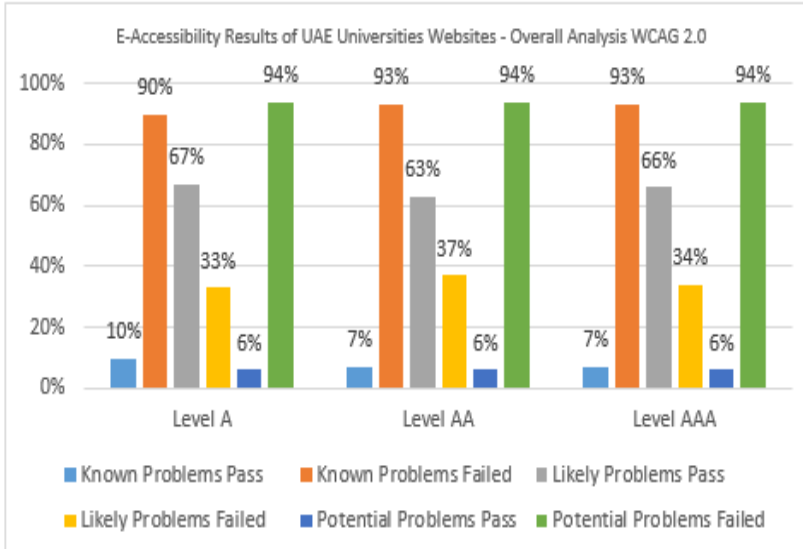

Fig. 4. E-accessibility results of UAE universities websites - Overall analysis WCAG 2.0. Source: Author of this research. 


\section{REASONS BEHIND THE FAILURE TESTED WEBSITES}

Below are the checkpoints that caused the failure of accessibility tests of university websites in the United Arab Emirates.

1) Text Alternatives: Provide text alternatives for any non-text content.

2) Ensure that information and structure can be separated from the presentation.

3) Distinguishable: Make it easier for users to see and hear content including separating foreground from background.

1) Keyboard Accessible: Make all functionality available from a keyboard.

2) Enough Time: Provide users enough time to read and use the content.

3) Navigable: Provide ways to help users navigate, find content, and determine where they are.

1) Readable: Make text content readable and understandable.

2) Input Assistance: Help users avoid and correct mistakes.

1) Compatible: Maximize compatibility with current and future user agents, including assistive technologies.

2) Adaptable: Create content that can be presented in different ways (for example simpler layout) without losing information or structure.

Fig. 5 below shows that:

- $70 \%$ of websites of the universities in UAE failed the accessibility validation test due to Level A Checkpoint 1.1 , text alternative for non-text content.

- $52 \%$ of websites of the universities in UAE failed the accessibility validation test due to Level A Checkpoint 1.3, ensuring information and structure could be separated from presentation.

- $49 \%$ of websites of the universities in UAE failed the accessibility validation test due to Level A checkpoint 1.4, making it easier for users to see and hear content including separating foreground from background.

$8 \%$ of websites of the universities in UAE failed the accessibility validation test due to Level A checkpoint 2.1, making all functionality available from a keyboard.

- 5\% websites of the universities in UAE failed the accessibility validation test due to Level A 2.2 checkpoint, providing users enough time to read and use the content.

- $63 \%$ websites of the universities in UAE failed the accessibility validation test due to Level A 2.4 checkpoint, providing ways to help users navigate, find content, and determine where they are.

- $21 \%$ websites of the universities in UAE failed the accessibility validation test due to Level A checkpoint 3.1, making text content readable and understandable for users.

- 59\% websites of universities in UAE failed the accessibility validation test due to Level A checkpoint 3.3 , helping users to avoid and correct mistakes.

- $36 \%$ websites of universities in UAE failed the accessibility validation test due to Level A checkpoint 4.1, maximizing compatibility with current and future user agents, including assistive technologies.
- $52 \%$ websites of universities in UAE failed the accessibility validation test due to Level AAA checkpoint 1.3 , creating content that can be presented in different ways (for example simpler layout) without losing information or structure.

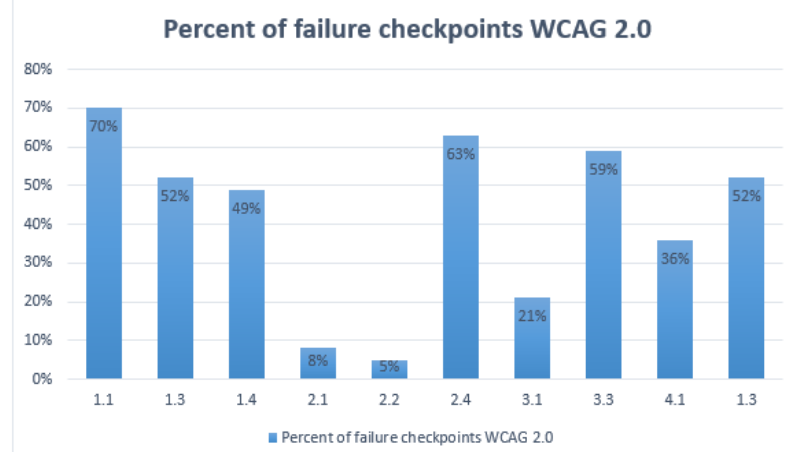

Fig. 5. Percent of failure checkpoints of WCAG 2.0. Source: Author of this research.

\section{CONCLUSION AND RECOMMENDATIONS}

There is a need for Web accessibility throughout the education system and in all domains since our modern daily lives heavily rely on e-technologies, and social media communications [14]. The consideration of E-accessibility guidelines is essential during the process of web development and design and for the success of any websites along with other factors such as usability, availability, reliability, and security. The World Wide Web is now becoming an important part of our life. Collection of information is right on the tip of our fingers and the use of WWW is growing at a very fast rate and the design for accessibility and usability is therefore of principal importance.

Much usability of websites could be achieved by implementing WCAG guidelines but achieving total E-accessibility is too difficult due to different types of disabilities and the requirements for different web users. For example, users who are trying to access the web through their mobile phones can advantage from it by being able to adjust the size of text or by using keystrokes to navigate through the web in the absence of a mouse [18]. Usability has to be universal and should provide for people with different disabilities, skills, knowledge, and culture. A more usable website will consequently be more accessible to a multitude of users.

Educational institutions play an integral role in our societies and learners with different types of disabilities and physical limitations now have the opportunity and equal rights to benefit from a wealth of information and services that were previously unavailable to them. The education system should teach and inform students the fundamental concepts and help them develop the ability to think from viewpoints across users [2]. In developed countries, the awareness of E-accessibility and its importance is now highly acknowledged and many legislations have been formed to make sure that special people are not discriminated against over the internet and now it is rising at all levels of society. However, underdeveloped countries have much to do when it comes to the issue of e-accessibility over the internet. 
Educational and all E-learning websites demand that all content available on their web pages must be accessible up to the required standards of Web Content Accessibility Guidelines defined by the World Wide Web Consortium (W3C).

The online environment must be accessible to all its visitors and therefore should not discriminate against particular users [19]. The problem of E-accessibility is that web developers and designers consider the issue of E-accessibility after developing and designing the website. Considering E-accessibility after the development of websites, applications, and other projects can lead to different barriers to E-accessibility. Therefore, E-accessibility should be considered at every stage of development of E-learning or any other projects. Considering E-accessibility after the development of a project can be more costly and time-consuming as well. Also, learning technologists have a responsibility of developing accessible electronic teaching material and resources for all users [20].

Based on the analysis of data collected through online validations test and manual checking of Universities websites in the United Arab Emirates and from the semi-structured interviews with the IT departments of the universities, this research recommends the followings to improve the level of E-accessibility;

Checkpoints which are the major reasons for the failure of the tested websites must be implemented appropriately to improve the level of E-accessibility. However, it is important to be considered that these recommendations could be implemented internationally while developing any website.

- Universities not only in the UAE but around the globe need to develop appropriate policies to make sure that the content of the websites and all other educational material is fully accessible to students with disabilities.

- Higher education in universities and other life-long learning open educational resources needs to be involved in the training and other awareness programs about the e-accessibility of their educational content.

- The developers and designers must be trained and they must be aware of the Web Content Accessibility Guidelines provided by the World Wide Web Consortium to make sure that appropriate implementations have been made when developing or designating the educational content of the university.

- Ministries of education around the globe and in UAE must consider the issue of e-accessibility to make sure that disabled students are not discriminated against when it comes to E-learning and E-education.

- Web developers must consider e-accessibility guidelines standardize by the World Wide Web Consortium and must implement them the process of design and development of websites to achieve the highest level of e-accessibility for students with special needs.

- It is the responsibility of the governmental institutions around the globe and in UAE to make sure that accessibility legislations are implemented appropriately. This will make sure the inclusion of all people to access educational, public, and governmental services without any physical limitations.

\section{Best Practices}

From the validations and tested websites of UAE through e-accessibility tools and also data collected through the manual checking and semi-structured interview, it was found that not all universities ignore the issues of e-accessibility and its importance for students with special needs. It was found that some of the universities are aware of the importance and they implemented e-accessibility standards in the design and development of their university websites very seriously. In addition, they put much effort to make sure that students can access the data when it comes to the e-learning environment. However, the number of these universities is very limited. Therefore, there is a need to increase awareness about the importance of e-accessibility standards and provide training to the developer of websites as well as to the students with special needs. Professors also need to be wary of the potential barriers of accessing content that hinder growth of knowledge and its application [21]. The following Fig. 6, 7, and 8 provide an example of the accessible websites that could be used as a model and where others need to improve on this.

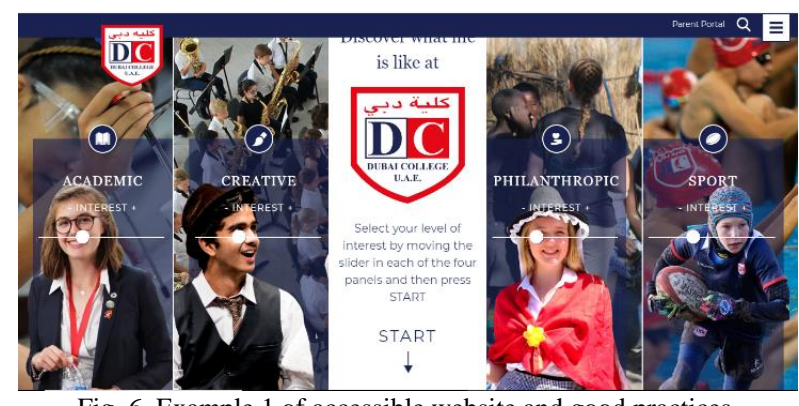

Fig. 6. Example 1 of accessible website and good practices.

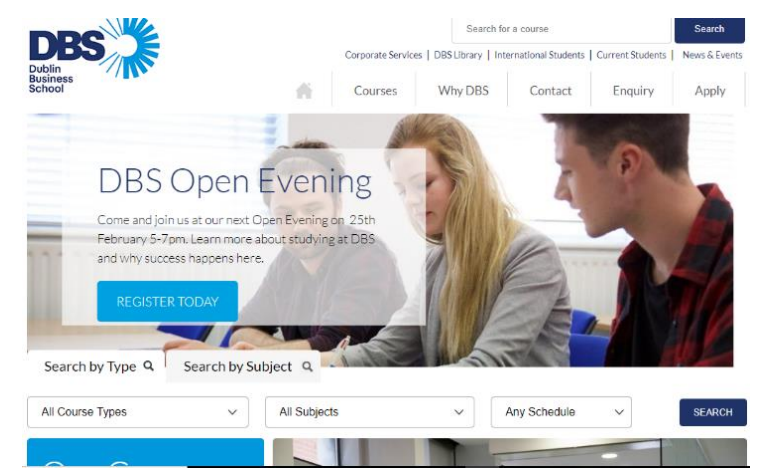

Fig. 7. Example 2 of accessible website and good practices.

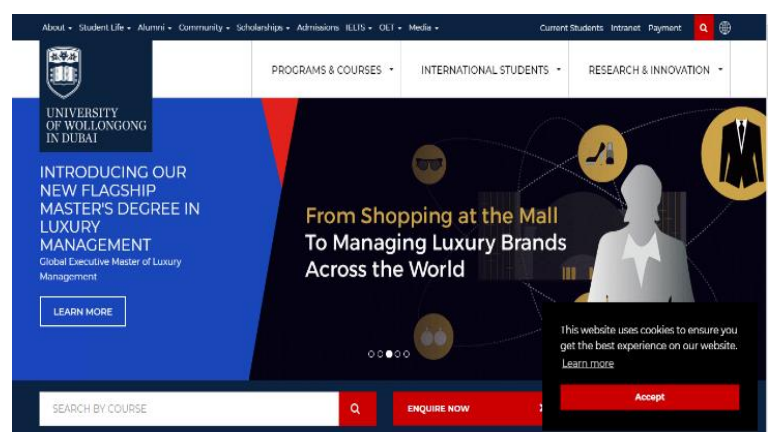

Fig. 8. Example 3 of accessible website and good practices.

\section{FUTURE WORK}

It is believed by the author of this research that more E-accessibility tests and validations both online and manual 
should be conducted to investigate the reasons for the failure of the websites in the educational sectors of UAE. This research just focused on university websites. Therefore, in future work, the websites of other educational institutions such as primary and secondary school websites should be considered. Failure checkpoints should be highlighted and recommendations should be formed to improve the level of E-accessibility across all educational institutions. The work should not be limited to educational sectors only. Both public and government websites should improve on the issue of E-accessibility.

\section{CONFLICT OF INTEREST}

The authors declare no conflict of interest.

\section{REFERENCES}

[1] T. Berners-Lee. (2018). World Wide Web Consortium, Leading the Web to Its Full Potential, Accessibility. [Online]. Available: https://www.w3.org/standards/webdesign/accessibility

[2] M. Kulkarni, "Digital accessibility: Challenges and opportunities," IIMB Management Review, vol. 31, issue 1, March 2019, pp. 91-98, 2019.

[3] N. E. Youngblood, "Integrating usability and accessibility into the interactive media and communication curriculum," Global Media Journal, ISSN: 1550-7521, 2020.

[4] W3C (1999) Web Content Accessibility Guidelines 1.0, W3C Recommendation 5-May-1999. [Online]. Available: https://www.w3.org/TR/WAI-WEBCONTENT/

[5] W3C (2008) Web Content Accessibility Guidelines (WCAG) 2.0, W3C Recommendation 11 December 2008. [Online]. Available: https://www.w3.org/TR/WCAG20/

[6] W3C (2018) Web Content Accessibility Guidelines (WCAG) 2.1, W3C Recommendation 05 June 2018. [Online]. Available: https://www.w3.org/TR/WCAG21/

[7] M. Alshamari, "Accessibility evaluation of arabic e-commerce web sites using automated tools," Journal of Software Engineering and Applications, vol. 9, pp. 439-451, 2016.

[8] M. Bakhsh and A. Mehmood, "Web accessibility for disabled: A case study of government websites in Pakistan," Research Gate, Frontiers of Information Technology (FIT), 2012, DOI: 10.1109/FIT.2012.68.

[9] P. A. P.-A. Cinquin, P. Guitton, and H. Sauzéon, "Online e-learning and cognitive disabilities: A systematic review," Computers and Education, Elsevier, 2019, vol. 130, pp. 152-167.

[10] WHO. (2012). Global data on visual impairments 2010. [Online]. Available:

https://www.who.int/blindness/GLOBALDATAFINALforweb.pdf
[11] WHO. (2019). Deafness and hearing loss. [Online]. Available: https://www.who.int/news-room/fact-sheets/detail/deafness-and-heari ng-loss

[12] NCES. (2019). Children and youth with disabilities, the condition of education. National Centre for Education Statistics. [Online]. Available: https://nces.ed.gov/programs/coe/indicator_cgg.asp

[13] W3C. (2019). Web Accessibility Evaluation Tools List. [Online]. Available: https://www.w3.org/WAI/ER/tools/

[14] B. A. Shawar, "Evaluating web accessibility of educational websites," International Journal of Emerging Technologies in Learning (iJET), eISSN: 1863-0383, vol. 10, no. 4, 2015.

[15] (2019). UAE Federal Government Web Guidelines, Ministry of Cabinet Affairs, United Araba Emirates. [Online]. Available: file:///C:/Users/l.ali/Downloads/1Web_Guidelines_Manual_English.p df

[16] M. Yousef, Children with Disability in the United Arab Emirates and the Services they Receive, GU Certificate in Early Intervention, Physical Therapists, Sharjah City for Humanitarian Services (SCHS), 2015.

[17] MOCD, Statistics, Ministry of Community Development, United Arab Emirates, 2019.

[18] J. Nielsen, Usability 101: Introduction to Usability, 2003.

[19] N. Sabev, G. Georgieva-Tsaneva, and G. Bogdanova, "Research, analysis, and evaluation of web accessibility for a selected group of public websites in Bulgaria," Journal of Accessibility and Design for All, vol. 10, no. 1, pp. 124-160, 2020.

[20] S. Jane, "The development of accessibility practices in e-learning: An exploration of communities of practice," $A L T-J$, vol. 12 , no. 1, pp. 51-63, 2004

[21] L. R. Massengale and E. Vasquez, "Assessing accessibility: How accessible are online courses for students with disabilities?" Journal of the Scholarship of Teaching and Learning, vol. 16, no. 1, February 2016, pp. 69-79.

Copyright (C) 2021 by the authors. This is an open access article distributed under the Creative Commons Attribution License which permits unrestricted use, distribution, and reproduction in any medium, provided the original work is properly cited (CC BY 4.0).

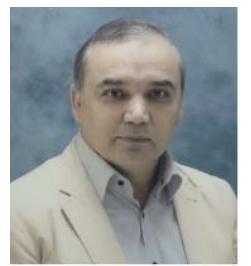

Liaqat Ali completed his $\mathrm{PhD}$, information systems in 2008 from University of East London UK. He was associated with many international universities since 2005 and had supervised more than 125 postgraduate research thesis. He is currently working in University of Science and Technology of Fujairah UAE. Dr Ali's principal research area for a number of years has been in the field of IS, e-accessibility and web development, cyber-crimes and business information systems. His research activities covers e-accessibility, web development, cyber-crimes and computer security, business information systems and management information systems. For further information on Dr Ali's profile, please visit https://liaqat22.wixsite.com/drali 